\title{
ANÁLISE DA QUALIDADE DA ÁGUA EM POÇOS ARTESIANOS NA REGIÃO DE ROCA SALES, VALE DO TAQUARI
}

\author{
Marília Bagatini ${ }^{1}$, Victória Bonzanini ${ }^{2}$, Eniz Conceição Oliveira ${ }^{3}$
}

Resumo: A água é um bem precioso que deve ser consumido de forma racional, e sua má qualidade pode trazer riscos à saúde. É um bem difícil de se encontrar pura, até mesmo a água da chuva, ao cair, traz impurezas do ar nela dissolvidas. Devido ao baixo custo os poços artesianos são bastante utilizados como fonte de água potável. No estudo presente, realizaram-se análises da qualidade da água de 10 poços artesianos de Roca Sales, para verificar os parâmetros físicos e químicos, tais como, $\mathrm{pH}$, turbidez, cor, condutividade, dureza e sólidos totais. Buscou-se comparar as características das amostras com os padrões pré-estabelecidos pela Portaria do Ministério da Saúde no 2914/2011. Todos os resultados obtidos estão de acordo com os padrões de qualidade estabelecidos.

Palavras-chave: Água. Qualidade da água. Parâmetros físicos e químicos. Análise.

Abstract: Water is a precious commodity that must be consumed in a rational way, and its poor quality can bring health risks. It is a good difficult to find pure, even the rainwater, when falling, brings impurities from the air dissolved in it. Due to the low cost artesian wells are widely used as a source of drinking water. In the present study, water quality analyzes of Roca Sales 10 artesian wells were carried out, to verify the physical and chemical parameters, such as $\mathrm{pH}$, turbidity, color, conductivity, hardness and total solids. We attempted to compare the characteristics of the samples with the standards established by the Ordinance of the Ministry of Health $n^{\circ}$ 2914/2011. All results obtained are in accordance with established quality standards.

Keywords: Water. Water quality. Physico-chemical parameters. Analysis.

\section{INTRODUÇÃO}

A água, considerada nosso solvente universal, ocupa em torno de $75 \%$ da superfície da terra e dois terços do corpo humano (LIBÂNIO, 2008). Cerca de $97,5 \%$ da água é salgada e apenas 2,5\% corresponde à água doce no mundo, visto que $68,9 \%$ da água doce são de geleiras ou neve, $29,9 \%$ provém de fonte subterrânea e $0,3 \%$ de rios e

1 Curso de Engenharia Química - Univates, Lajeado/RS. E-mail: mariliabagatini@hotmail.com

2 Curso de Engenharia Química - Univates, Lajeado/RS. E-mail: vickbonzanini@gmail.com

3 Doutora em Química pela UFRGS. Professora titular da Univates. E-mail: eniz@univates.br 
lagos. Infelizmente, apenas $3 \%$ da água no planeta é própria para o consumo humano (ALMEIDA, 2010).

Segundo Azevedo (2014) o total de água disponível para o homem, está representado em maior quantidade pelas águas subterrâneas, com rios e lagos apresentando baixa proporção quando comparados às demais fontes. Ela é um recurso natural em grande abundância, embora uma pequena quantidade está disponível para consumo humano imediato, sendo indispensável adotar medidas preventivas para manter sua qualidade e corrigi-la, se necessário.

Assim como a evolução humana, os problemas ambientais também foram evoluindo e hoje sabemos que a água é o recurso natural mais afetado com o aumento da população e consequente aumento de consumo de água, intensificando a poluição. Diante das contaminações que vem ocorrendo, a água se tornou também um veículo para diversos tipos de doenças e nos últimos anos, uma das maiores problemáticas enfrentadas pelo ser humano é a qualidade e poluição da água. A contaminação pode prejudicar a saúde da população, gerar conflitos sociais e econômicos e principalmente prejudicar a biota, sendo a maior causadora de mortes e doenças no mundo, por isso os estudos relacionados à água e seus contaminantes são tão significativos.

É imprescindível destacarmos a preservação de recursos hídricos, pois segundo Lobo e Callegaro (2000) está se tornando um desafio encontrar água livre de contaminações. Grande parte destas contaminações está diretamente ligada a atividades industriais, descarte de resíduos de maneira inadequada, mudanças climáticas, urbanização, que acabam por alterar a qualidade da água.

A água subterrânea é um bem econômico e uma fonte necessária de abastecimento para o consumo humano, para comunidades que não possuem acesso à rede pública de abastecimento, ou até mesmo para os que a possuem, mas com irregularidade no fornecimento.

Uma das fontes mais utilizadas no mundo para consumo é a água subterrânea, sendo indispensável a verificação e acompanhamento de sua potabilidade, devido à utilização de substâncias químicas com concentrações fora dos padrões permitidos pela Portaria 2914/2011 (BRASIL, 2011), e pela sua capacidade de transmissão de doenças causadas por microrganismos patogênicos de fezes.

O Brasil possui legislações específicas voltadas para a qualidade da água. Entre elas está a Resolução do Conselho Nacional do Meio Ambiente (CONAMA) no 357, de 2005, e a Portaria do Ministério da Saúde n 2914/2011 (BRASIL, 2011), as quais possuem classificações e orientações ambientais estabelecendo os limites máximos de cada substância a ser analisada para se obter uma água de qualidade, sendo essa análise realizada através de parâmetros físico-químicos e microbiológicos.

O objetivo deste trabalho foi analisar parâmetros físicos e químicos da água em dez poços artesianos, localizados no município de Roca Sales, Rio Grande do Sul, a 
fim de realizar um comparativo entre os parâmetros determinados pela Portaria do Ministério da Saúde no 2.914 de 12 de dezembro de 2011 (BRASIL, 2011).

\section{MATERIAL E MÉTODOS}

Em 2017, na disciplina Análise Quantitativa II, da Univates, realizou-se um estudo da análise de água de dez poços artesianos da cidade de Roca Sales, localizado no Vale do Taquari. As coordenadas dos pontos de coletas foram obtidas com um GPS Garmin Nuvi, modelo 1100LM. A Figura 1 mostra a localização e o Quadro 1 apresenta as coordenadas dos dez pontos amostrados.

Quadro 1 - Localização dos dez pontos amostrados e suas coordenadas, no município de Roca Sales, em abril de 2017

\begin{tabular}{|c|c|c|}
\hline Amostra & Localização & Coordenadas \\
\hline 1 & Arroio Augusta Alta & $\begin{array}{c}29^{\circ} 14^{\prime} 594^{\prime \prime} \mathrm{S} \\
051^{\circ} 47^{\prime} 317^{\prime \prime} \mathrm{W}\end{array}$ \\
\hline 2 & Arroio Augusta Baixa & $\begin{array}{c}29^{\circ} 15^{\prime} 134^{\prime \prime} \mathrm{S} \\
051^{\circ} 46^{\prime} 235^{\prime \prime} \mathrm{W} \\
\end{array}$ \\
\hline 3 & Constância & $\begin{array}{c}29^{\circ} 17^{\prime} 567 ” \mathrm{~S} \\
051^{\circ} 50^{\prime} 157^{\prime \prime} \mathrm{W}\end{array}$ \\
\hline 4 & Arroio Augusta Média & $\begin{array}{c}29^{\circ} 15^{\prime} 143^{\prime \prime} \mathrm{S} \\
051^{\circ} 47^{\prime} 499^{\prime \prime} \mathrm{W}\end{array}$ \\
\hline 5 & Linha 21 de Abril & $\begin{aligned} 29^{\circ} & 18 ' 144^{\prime \prime} \mathrm{S} \\
051^{\circ} & 53^{\prime} 132 ” \mathrm{~W}\end{aligned}$ \\
\hline 6 & Praça Local & $\begin{array}{c}29^{\circ} 17^{\prime} 340 ” \mathrm{~S} \\
051^{\circ} 52^{\prime} 910 ” \mathrm{~W}\end{array}$ \\
\hline 7 & Linha Júlio Baixa & $\begin{array}{c}29^{\circ} 18^{\prime} 567^{\prime \prime} \mathrm{S} \\
051^{\circ} 50^{\prime} 157^{\prime \prime} \mathrm{W}\end{array}$ \\
\hline 8 & Linha Brasil & $\begin{array}{c}29^{\circ} 16^{\prime} 463 ” \mathrm{~S} \\
051^{\circ} 49^{\prime} 073^{\prime \prime} \mathrm{W}\end{array}$ \\
\hline 9 & Loteamento & $\begin{array}{c}29^{\circ} 17^{\prime} 391^{\prime \prime S} \\
051^{\circ} 52^{\prime} 227^{\prime \prime W} \\
\end{array}$ \\
\hline 10 & Linha Júlio Alta & $\begin{array}{r}29^{\circ} 17^{\prime} 358^{\prime \prime S} \\
051^{\circ} 47^{\prime} 571^{\prime \prime W}\end{array}$ \\
\hline
\end{tabular}

Fonte: Da autora (2017). 
Figura 1 - Localização dos pontos de coleta no município Roca Sales

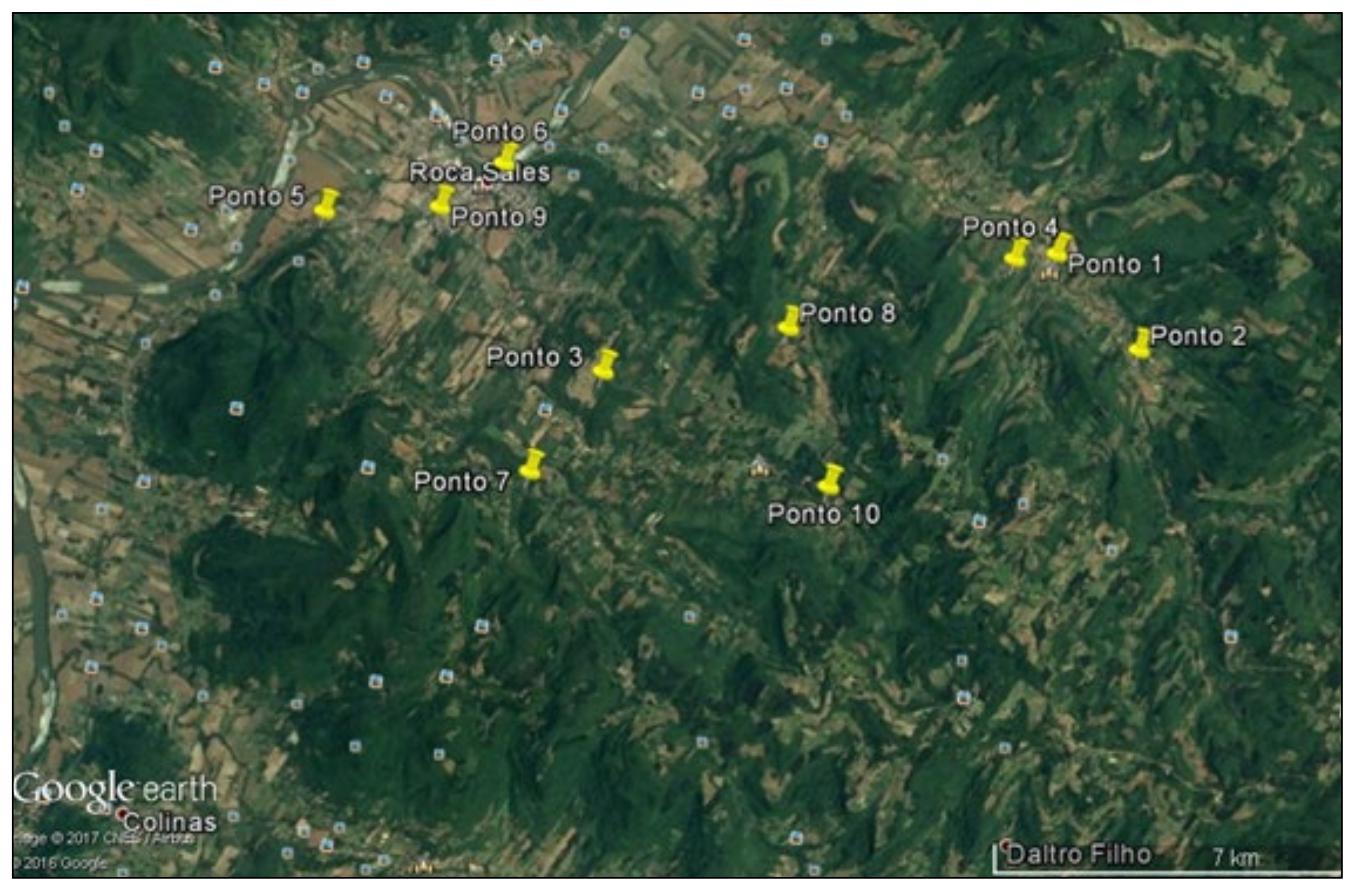

Fonte: Adaptado de Google Earth (2017).

A coleta das amostras foi realizada em frascos de polietileno, limpos e identificados contendo um volume de 1 litro, sendo executadas na residência mais próxima ao poço. In loco, foi realizada a medição da temperatura da água nos pontos de coleta, com termômetro de vidro de coluna de mercúrio, e também a medição do oxigênio dissolvido, com o oxímetro digital da marca Digimed, modelo DM-4P. As amostras foram colocadas em recipiente térmico para posterior análise, sendo estas realizadas no laboratório da Univates.

Para a medição da turbidez, $\mathrm{pH}$, cor, condutividade, dureza e sólidos totais, as amostras coletadas foram homogeneizadas e utilizou-se os seguintes equipamentos da marca Digimed: turbidímetro, modelo DM-TU Digicrom Analytical, medidor de pH modelo DM-22, condutivímetro modelo DM-32, calorímetro modelo DM-COR Digicrom Analytical.

A análise de dureza foi realizada à temperatura ambiente, sendo estas feitas em triplicata, por método titulométrico, de acordo com as normas (RICE et al., 2012).

Nos sólidos totais, pelo método gravimétrico, foram utilizadas cápsulas de porcelana, realizando o aquecimento em estufa com uma variação de temperatura entre $103^{\circ} \mathrm{C}$ a $105^{\circ} \mathrm{C}$, posteriormente sendo resfriadas à temperatura ambiente em um dessecador e realizando-se as medidas de massa. 


\section{RESULTADOS E DISCUSSÕES}

Tabela 1 - Parâmetros de temperatura da água (TA) e ambiente (T), oxigênio dissolvido (OD), $\mathrm{pH}$, turbidez, colorimetria, condutividade para as amostras de água avaliadas

\begin{tabular}{c|c|c|c|c|c|c|c}
\hline Amostra & $\mathrm{TA}\left({ }^{\circ} \mathrm{C}\right)$ & $\mathrm{T}\left({ }^{\circ} \mathrm{C}\right)$ & $\mathrm{OD}(\mathrm{mg} / \mathrm{L})$ & $\mathrm{pH}$ & $\begin{array}{c}\text { Turbidez } \\
(\mathrm{NTU})\end{array}$ & $\begin{array}{c}\text { Colorimetria } \\
(\mathrm{PT}-\mathrm{Co} / \mathrm{L})\end{array}$ & $\begin{array}{c}\text { Condutividade } \\
(\mu \mathrm{s} / \mathrm{cm})\end{array}$ \\
\hline 1 & 20 & 20,1 & 8,72 & 7,27 & 0,02 & 13,7 & 707,9 \\
\hline 2 & 20 & 20,5 & 7,1 & 7,5 & 0,08 & 12,8 & 262,4 \\
\hline 3 & 20 & 22,9 & 8,4 & 7,74 & 0,28 & 13 & 288,2 \\
\hline 4 & 19 & 21,1 & 6,89 & 7,74 & 0,44 & 13,62 & 504,4 \\
\hline 5 & 19 & 24,3 & 7,56 & 8,21 & 0,38 & 12 & 422,1 \\
\hline 6 & 22 & 22,5 & 7,7 & 7,8 & 0,15 & 12,9 & 291,4 \\
\hline 7 & 22 & 21,6 & 7,63 & 7,65 & 0,02 & 14,5 & 172,23 \\
\hline 8 & 21 & 23,3 & 7,84 & 8,08 & 0,02 & 13,3 & 254,5 \\
\hline 9 & 24 & 22,7 & 7,78 & 7,62 & 0,02 & 13,3 & 197,35 \\
\hline 10 & 24 & 21,5 & 8,44 & 6,68 & 0,15 & 14 & 72,76 \\
\hline
\end{tabular}

Fonte: Da autora (2017).

O oxigênio dissolvido medido no momento da coleta teve variações de $6 \mathrm{mg} / \mathrm{L}$ a $8,72 \mathrm{mg} / \mathrm{L}$, e de acordo com a legislação, as amostras não podem ter oxigênio dissolvido menor que $6 \mathrm{mg} / \mathrm{L}$, logo todas as amostras coletas se enquadram na Classe 1 , segundo o parâmetro do oxigênio dissolvido.

No $\mathrm{pH}$, que representa a concentração de íons hidrogênio, é uma medida que deve ser acompanhada para melhorar processos de tratamento e evitar corrosões ou entupimentos nas tubulações, obteve-se uma variação de 6,68 a 8,21. Sendo de acordo com o padrão de classificação e potabilidade da água, segundo a Portaria do Ministério da Saúde no 2914/2011 (BRASIL, 2011), onde o pH da água deve ser mantido na faixa de 6 a 9,5 no sistema de distribuição.

A turbidez indica o grau de atenuação em que o feixe de luz sofre ao atravessar a água, que ocorre pela absorção e espalhamento da luz causada pelos sólidos em suspensão, reduzindo sua transparência. $\mathrm{O}$ aumento de turbidez ocasiona em um uso maior de produtos químicos no tratamento da água. $\mathrm{O}$ valor máximo permitido para turbidez é 1,0 para água subterrânea desinfetada e 5 como padrão de aceitação para consumo humano. A Portaria do Ministério da Saúde no 2914/2011 (BRASIL, 2011) prevê que valores para a turbidez não podem ultrapassar 5,0 NTU (Unidade de Turbidez).

A colorimetria, que é a medição da intensidade de luz transmitida por uma solução, devido a presença de sólidos dissolvidos, segundo a legislação os índices máximos para 
colorimetria é de $15 \mathrm{mg} \mathrm{Pt-Co/L}$. A cor e a turbidez podem ser relacionadas, pois os dois parâmetros indicam presença de sólidos em suspensão. Todos os valores de turbidez e cor obtidos para as amostras em estudo estão de acordo com a resolução citada anteriormente.

Quanto à condutividade não há referências de máximo ou mínimo permitido na portaria. Conforme Lima e Garcia (2008), a condutividade pode ser utilizada na contribuição para reconhecer impactos ambientais que possam ocorrer na água devido a lançamentos de esgotos e resíduos industriais. A Tabela 2 apresenta os resultados de dureza e sólidos totais para as amostras de águas avaliadas.

Tabela 2 - Parâmetros de dureza e sólidos totais para as amostras de água estudadas

\begin{tabular}{c|c|c|c}
\hline Amostra & $\begin{array}{c}\text { Dureza } \\
\left(\mathrm{mg} \mathrm{CaCO}_{3} / \mathrm{L}\right)\end{array}$ & Desvio Padrão & $\begin{array}{c}\text { Sólidos Totais } \\
(\mathrm{mg} / \mathrm{L})\end{array}$ \\
\hline 1 & 153,30 & 0,16 & 0,2133 \\
\hline 2 & 161,34 & 0,17 & 0,1933 \\
\hline 3 & 182,16 & 0,05 & 0,1533 \\
\hline 4 & 292,26 & 0,20 & 0,3533 \\
\hline 5 & 209,38 & 0,25 & 0,3600 \\
\hline 6 & 177,35 & 0,12 & 0,3600 \\
\hline 7 & 116,10 & 0,20 & 0,0733 \\
\hline 8 & 154,53 & 0,12 & 0,0400 \\
\hline 9 & 125,31 & 0,21 & 0,0133 \\
\hline 10 & 78,47 & 0,06 & 0,0266 \\
\hline
\end{tabular}

Fonte: Da autora (2017).

Dureza da água nada mais é que a concentração de cátions multivalentes em solução na água, sendo os mais associados a dureza o Cálcio e Magnésio. As águas que possuem uma dureza elevada reduzem a formação de espuma, necessitando um maior consumo de sabões e xampus, impossibilita seu uso em diversas utilidades, e além disso pode causar incrustações em tubulações, muitas vezes acarretando em entupimentos (BRASIL, 2014). Por isso a necessidade de realizar-se um tratamento em águas muito duras antes de sua utilização.

A dureza da água é geralmente causada pela presença de sais de Cálcio e de Magnésio, uma água é considerada "dura" quando contém na sua composição valores significativos, de 150 a $300 \mathrm{mg} / \mathrm{L} \mathrm{CaCO}_{3}$ e "macia" quando os contém em pequenas quantidades, de 0 a $50 \mathrm{mg} / \mathrm{L}$, de acordo com Baird e Cann (2005).

$\mathrm{Na}$ análise da dureza da água, averiguamos a presença de sais de Cálcio e Magnésio, sendo considera "dura" quando a mesma contém altos valores destes sais e "macia" 
quando em pequenas quantidades. A Portaria do Ministério da Saúde no 2914/2011 (BRASIL, 2011) determina que a concentração da dureza não pode ser superior a $500 \mathrm{mg} / \mathrm{L}$. De acordo com Baird e Cann (2005), a água é considerada moderadamente dura de $50 \mathrm{mg} / \mathrm{L}$ a $150 \mathrm{mg} / \mathrm{L}$ e considera-se água dura as que se encontram entre 150 $\mathrm{mg} / \mathrm{L}$ e $300 \mathrm{mg} / \mathrm{L}$. Portanto, as amostras 7, 9 e 10 são consideradas moderadamente duras, sendo todas as outras amostras duras. Entretanto, todas as amostras estão de acordo com a legislação, sendo assim consideradas água potável.

$\mathrm{Na}$ determinação de sólidos na água são empregados métodos gravimétricos. Sólido é considerada toda a matéria que se mantêm como resíduo, após os processos de evaporação, secagem ou calcinação, em uma determinada temperatura e tempo. Os sólidos totais das dez amostras ficaram muito abaixo do valor máximo permitido pela legislação, em que é estabelecido pela Portaria do Ministério da Saúde n 2914/2011 (BRASIL, 2011) o máximo de $1000 \mathrm{mg} / \mathrm{L}$.

Nas análises realizadas nos poços artesianos de Roca Sales obteve-se uma média de dureza de 165,02 mg/L $\mathrm{CaCO}_{3}$, considerando-se uma água "dura", sendo todos os parâmetros analisados dentro das legislações vigentes. Pode-se comparar com as análises em poços artesianos no município de Imigrante realizadas por Zerwes et al. (2015), que obtiveram resultados de acordo com a legislação, sendo apenas alguns poços em desacordo para os parâmetros de turbidez e cor, tendo uma média de dureza de $121,13 \mathrm{mg} / \mathrm{L} \mathrm{CaCO}_{3}$, considerando-se uma água moderadamente "dura". Nesse comparativo verifica-se que há uma variação das médias de dureza, isto é, devido à dureza da água variar geograficamente, devido à natureza geológica do solo por onde a água passa e tem contato. Uma água dura está associada a zonas onde os solos são de natureza calcária, e uma água macia, a zonas onde os solos são de natureza granítica ou basáltica. Em geral, as águas subterrâneas, pelo seu maior contato com as formações geológicas, são mais duras.

\section{CONCLUSÃO}

Segundo Macêdo (2001), em suas características físicas, espera-se que a água seja transparente, sem sabor, cor e odor para estar adequada ao consumo humano, já os parâmetros químicos, muito importantes na caracterização da qualidade da água, permitem determinar o grau de contaminação, caracterizar a concentração de poluentes tóxicos e suas possíveis fontes.

Diversos fatores podem influenciar no comprometimento da qualidade da água subterrânea, uma das fontes mais utilizadas para os abastecimentos. As características da água podem variar de acordo com o local e as condições de origem.

No presente trabalho averiguou-se que os parâmetros físicos e químicos, dureza e sólidos totais das amostras analisadas se encontram dentro dos padrões exigidos pela Portaria do Ministério da Saúde n²914/2011 (BRASIL, 2011). Portanto, as águas dos 
poços artesianos em que foram realizadas as análises estão de acordo com a legislação vigente dos padrões de potabilidade, para os parâmetros analisados.

\section{REFERÊNCIAS}

ALMEIDA, M. Geografia Global 2. São Paulo: Escala Educacional, 2010.

AZEVEDO, Juliana de Souza; FRESQUI, Maíra; TRSIC, Milan. Curso de química para engenharia, água. São Paulo: Manole, 2014. v. 3.

BAIRD, Colin; CANN, Michael. Environmental chemistry. 3th ed. New York: W. H. Freeman, 2005.

BRASIL. Ministério da Saúde. Fundação Nacional de saúde. Manual de controle da qualidade de água para técnicos que trabalham em ETAs. Brasília: Funasa, 2014.

BRASIL. Ministério da Saúde. Portaria n. 2.914, de 12 de dezembro de 2011. Disponível em: <http://bvsms.saude.gov.br/bvs/saudelegis/gm./2011/prt2914_12_12_2011.html>. Acesso em: 25 maio 2017.

BRASIL. Conama. Resolução no 357, de 17 de março de 2005. Dispõe sobre a classificação dos corpos de água e diretrizes ambientais para o seu enquadramento, bem como estabelece as condições e padrões de lançamento de efluentes, e dá outras providências. Brasília, 2011. Disponível em: <http:/www.mma.gov.br/port/conama/res/res05/res35705.pdf>. Acesso em: 25 mai. 2017.

LIBÂNIO, M. Fundamentos de qualidade e tratamento de água. 2. ed. São Paulo: Átomo, 2008.

LIMA, W. S.; GARCIA, C. A. B. Qualidade da água em Ribeirópolis-SE: o açude do cajueiro e a barragem do João Ferreira. Scientia Plena, Sergipe, v. 4, n. 12, p.1-24, dez. 2008.

LOBO, E. A., CALLEGARO, V. L. Avaliação da qualidade de águas doces continentais com base em algas diatomáceas epilíticas: enfoque metodológico. In TUCCI, C. E. M; MARQUES, D. M. (Org). Avaliação e controle da Drenagem Urbana. Porto Alegre: Ed. Universidade/UFRGS, p. 277 - 300. 2000.

MACEDO, J. A. B. de. Águas \& águas. São Paulo: Varela, 2001.

RICE, E. W. et al. Standard methods for the examination of water and wastewater. 22. ed. Washington (DC): American Public Health Association, 2012.

ZERWES, Cristian M. et al. Análise da qualidade da água de poços artesianos do município de Imigrante, Vale do Taquari/RS. Ciência e Natura, 2015. 